\title{
Managing Graphics Training in Digitalized Environment
}

\author{
Irina Stolbova ${ }^{1}$ and Olga Pichkaleva ${ }^{1}$ \\ ${ }^{1}$ Perm National Research Polytechnic University, Komsomolsky pr. 29, Perm, 314990, Russia
}

\begin{abstract}
The article is devoted to the management of subject learning based on the principle of individualization in the context of the digital transformation of the educational process. Individualized learning technologies help increase student interest in achieving better results. The expediency of using such learning technologies that are focused on individualization has been proven, since individually oriented learning helps to stimulate students to achieve better results. Basic graphic preparation of students is used as an example of subject preparation. There is an example of a prepared educational resource-an electronic workshop, which presents a database of geometric problems with creative content. The necessity of using a practiceoriented project task for the purpose of introducing to professional creativity and mastering methodology of independent work with maximum disclosure of their individual potential is shown. The scheme of working at a project in a digital environment is considered. The target settings of subject-based learning are highlighted. The network schedule of planning individual work of students taking into account different levels of immersion in project activities is discussed. The authors demonstrate a set of tasks for the design of $3 \mathrm{~d}$ models of objects of varying complexity, contributing to the formation of competencies in the practical implementation of algorithms for geometric constructions. It is concluded that the use of electronic educational resources in the process of basic geometric and graphic training makes it possible to bring the training support closer to the real professional design environment as well as introduces students to the latest innovative technologies.
\end{abstract}

\section{Keywords}

Digitalization, geometric and graphic preparation, individualization, project assignment.

\section{Introduction}

Thanks to the comprehensive process of informatization, human activity has changed in all spheres of life, the potential for innovative changes in industrial technologies has appeared, which ensured the onset of a new period of development - the era of global digitalization [1]. The issues of training indemand personnel, modernization of the vocational education system, changes in educational programs in accordance with the demands of the labor market, the introduction of digital tools for educational activities, and the creation of an electronic learning environment are becoming topical.

Training based on the competence format of the current educational standards involves taking into account the personal characteristics of students, among which the ability to learn, the need for selfdevelopment, active achievement of the set goals are especially important [2]. Individually oriented learning technologies, educational procedures that stimulate motivation to achieve better results, as well as differentiating opportunities to take into account personal characteristics and the current level of results achieved, are becoming in demand.

At present, for modern engineering education in the preparation of specialists and in the organization of vocational training, a special requirement is the orientation of the educational process to project activities. Until now, training in this subject is reproductive in nature. With this nature of teaching, students are supposed to reproduce the material that was presented by the teacher, and only the proposed

GraphiCon 2021: 31st International Conference on Computer Graphics and Vision, September 27-30, 2021, Nizhny Novgorod, Russia EMAIL: stolbova.irina@gmail.com (I. D. Stolbova); sitnikova89@mail.ru (O. A. Pichkaleva) ORCID: 0000-0002-0546-9428 (I. D. Stolbova); 0000-0002-7788-855X (O. A. Pichkaleva)

(c) (i) 2021 Copyright for this paper by its authors.

Use permitted under Creative Commons License Attribution 4.0 International (CC BY 4.0).

CEUR Workshop Proceedings (CEUR-WS.org) 
algorithm for performing operations is used $[3,4]$. This type of training does not contribute to the proper development of the student's abilities for independent learning and mastering professional competencies. In the course of the educational process and the immersion of students in the technology of project activities, a professional model of behavior of the future graduate should gradually be formed [5].

The modern educational system of higher education should guarantee a confident transition to the digital age, provide training for specialists with digital literacy, who are fluent and fluent in Internet technologies. To organize student training in the electronic educational environment (EEE), it is necessary to create appropriate opportunities for the implementation of innovative technologies, the most significant of which [1]:

- advanced training of university teachers in the use of digital technologies in the field of educational activities;

- for the availability of educational resources and the implementation of continuous monitoring of students' progress, the creation of a developed system of networked educational services;

- development of methodological and didactic materials, ranked according to their compliance with the assigned criteria;

- $\quad$ organization of a feedback management system, including user authorization, content, testing, personal and collective space.

In the graphic preparation of students of technical universities, a wide range of modern CAD capabilities is used, which provide an innovative quality of teaching methods, as well as a higher level of students' preparation for modern design and engineering activities [6, 7]. The competence model of graphic education is implemented on the basis of the integration of the theoretical foundations of geometric modeling and modern CAD tools, the main tool of which is project learning $[8,9]$. The innovativeness of the learning process lies in the organization of educational practical activities on the basis of a harmonious connection between theory and practice, as well as stimulating the student to constantly "obtain" the required information through the electronic learning environment. This is facilitated by the developed complex tasks that integrate various sections of the discipline and imitate quasi-professional design activities [10,11].

In this paper, the authors consider the issues of individualization and management of subject training in the context of digitalization on the example of basic geometric and graphic training of students of a technical university, which is carried out for all areas in the field of engineering and technology in the junior years of the university.

\section{Digital support of geometric and graphic training}

Currently, the geometric-graphic training (GGT) of students of a technical university involves the formation of the readiness of future graduates for design and engineering activities. Teaching students using a project-based approach makes it possible to simulate the immersion of students in the future sphere of production functionality in the learning process. This area ensures the development of students in terms of design and engineering competencies. That corresponds to the passage of an individual educational trajectory, taking into account the personal qualities of the student and his current achievements [1].

To date, GGT is an organic combination of traditional techniques and innovative digital technologies. At each step of the educational process, the feasibility of using digitalization is investigated both in mastering educational material and in monitoring the success of the formation of geometric-graphic competencies of students.

At the Perm National Research Polytechnic University, when developing an innovative course in graphic education, special attention was paid to the development of practical methods of using computer graphics. A laboratory workshop was introduced into the training program, where the issues of not only the automated release of design documentation (synthesis of engineering and computer graphics) are considered, but also practice-oriented problems of geometric modeling are solved, combining the theoretical foundations of descriptive geometry and modern CAD tools [10].

The basic theoretical knowledge acquired by students and the skills they have acquired to solve practice-oriented problems are practically implemented using $2 \mathrm{D}$ and $3 \mathrm{D}$ technologies through a 
prepared educational resource - an electronic workshop, which presents a base of geometric problems with creative content. The used workshop contains tasks of various levels of complexity, which are modern analogues of metric and positional problems. The tasks develop the spatial imagination of trainees, demonstrate the need to master the basics of descriptive geometry and at the same time improve the skills of using $3 \mathrm{~d}$ modeling tools [7].

Within the framework of the program of geometric-graphic training, a fairly large volume of individual independent work of students is provided, carried out outside of school hours. With this type of educational activity, the components of competencies are consolidated, such as knowledge, skill, skills and work experience. Also, with this type of educational activity, the formation of geometric and graphic competencies in general occurs. For this purpose, special individual thematic tasks have been developed.

Each of the many practice-oriented project tasks is of a complex nature, combines one or more topics of the discipline being studied and is aimed at forming a certain part of the subject competencies. At the beginning of the training, the student receives an individual version with initial plans, but execution is performed according to a single algorithm. As you master the discipline, the content of tasks becomes more complicated and different levels of its implementation are assumed. The final tasks may be in the nature of a course project, during which the student must demonstrate the final level of formation of geometric and graphic competencies. Thus, the student is involved in professional creativity, having the opportunity to maximize his individual potential in the course of independent work [4].

Information support for the implementation of the final project assignment for the course of study is carried out through an electronic learning environment. This section of EEE contains all the necessary information and reference resources, specialized libraries, as well as a project progress management system. Figure 1 demonstrates the scheme of work on the project, which is prepared in a digital environment. The support methodology best allows students to demonstrate their readiness for design activities. $[1,12]$.

An important component of the educational process is the organization of control over the success of mastering the training program. In the era of digitalization, the wide possibilities of modern information and communication technologies provide innovative means of assessing the achieved educational results. Automation of control of knowledge and skills allows for end-to-end monitoring of students 'progress at all stages of mastering the educational program, and also makes it possible to introduce self-control within the framework of students' independent work. Processing and analysis of the results of the conducted control tests allows you to develop corrective actions on the current situation in the framework of subject training as a whole, in individual student groups and the progress of a particular student $[10,13]$.

\section{Individualization of independent work based on network modeling}

The modern concept of subject learning development involves introduction of variable forms of organization of the educational process based on personalization of approaches to students and the individualization of educational trajectories, taking into account personal qualities, learning abilities, interests and needs.

As target settings of the subject training, 3 levels of mastering the subject area can be selected, which correspond to three basic educational routes, implying a different degree of deepening into project activities:

- The first level of mastering is to solve standard practice-oriented problems of the reproductive nature.

- The second level of mastering includes the solution of project assignments of a problem nature.

- The third level of development involves the implementation of projects with a heuristic orientation. 


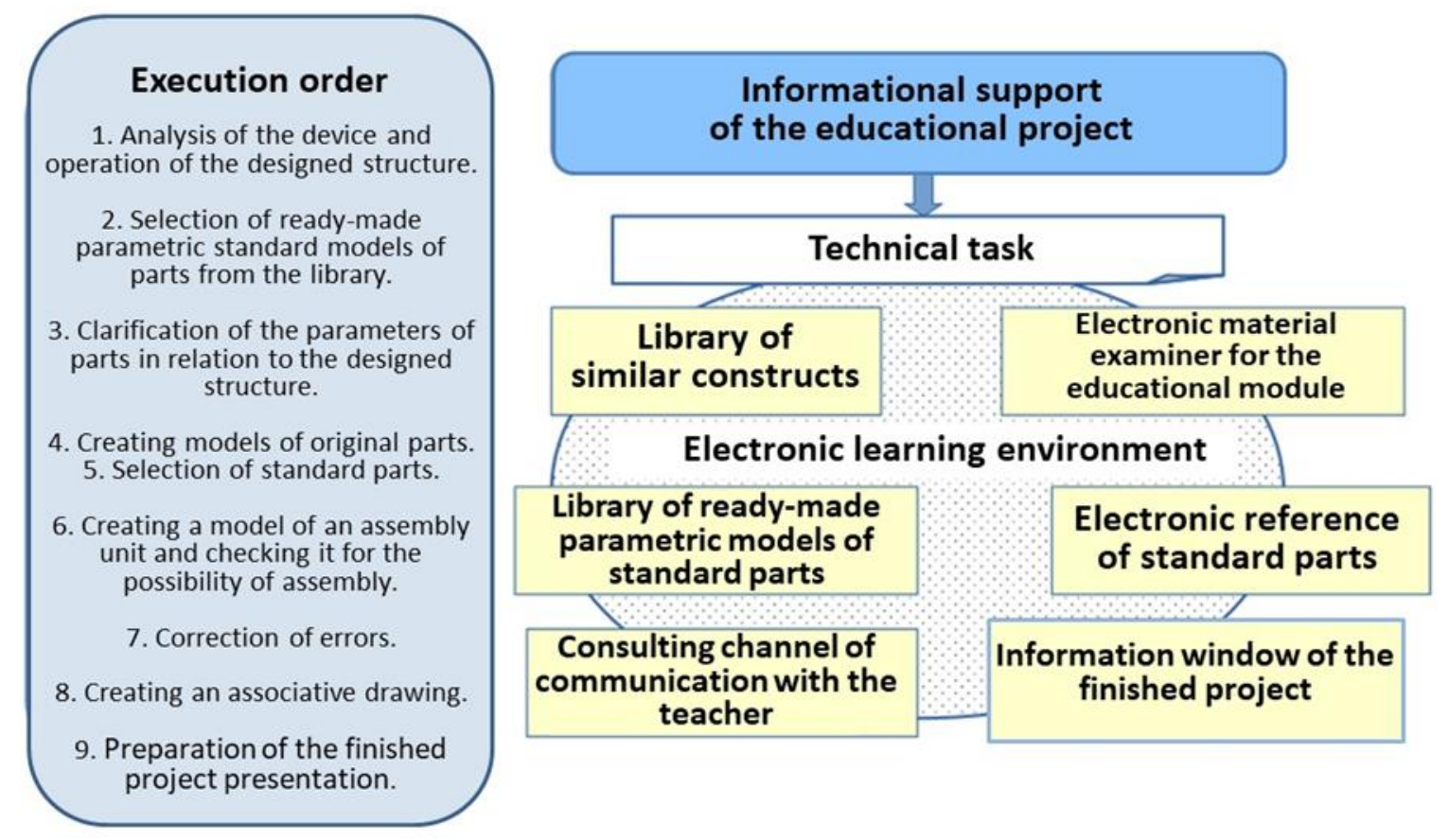

Figure 1: Working on a project in a digital environment

The individual abilities of students and, accordingly, the achieved level of completion of the training program are best shown in the course of individual independent work. Comprehensive assessment of the planned results of the subject training is carried out on the basis of specially developed educational tasks (projects) independently completed by students. The tasks presented in the thematic projects can be differentiated by difficulty levels by taking into account the personal characteristics of students and their motivation.

Figure 2 shows a network schedule for planning individual work of students, taking into account different levels of immersion in project activities [4]. The initial level of readiness of students is marked in the figure as P0. This level assumes the possibility of choosing a basic educational route. On each basic route, the process of working on an individual task is indicated by an arrow. Graph nodes show current student learning outcomes. The results achieved so far may be determined by additional transitions between the base routes. Solid arrows indicate increase of mastering, while dashed arrows show its lowering. The end points of the educational routes show the level of mastering of the subject area. To master the subject area on the 1st educational route, one needs to perform simple tasks. The expanding bands show tasks that relate to the formation of the same part of subject competencies. The depth of mastering the material and part of the competencies in Figure 2 is shown by the expansion of the band.

When analyzing the network schedule for planning the graphic training of students, one can notice that at the beginning of the second and third routes, a certain number of thematic tasks are not observed. This is due to the fact that students have a higher level of initial training, which may indicate a high level of school education, or that the student has secondary vocational education. In the future, the definition of the educational route may depend both on the initial preparation of the student and on the results of the current control of the mastery of the material. 


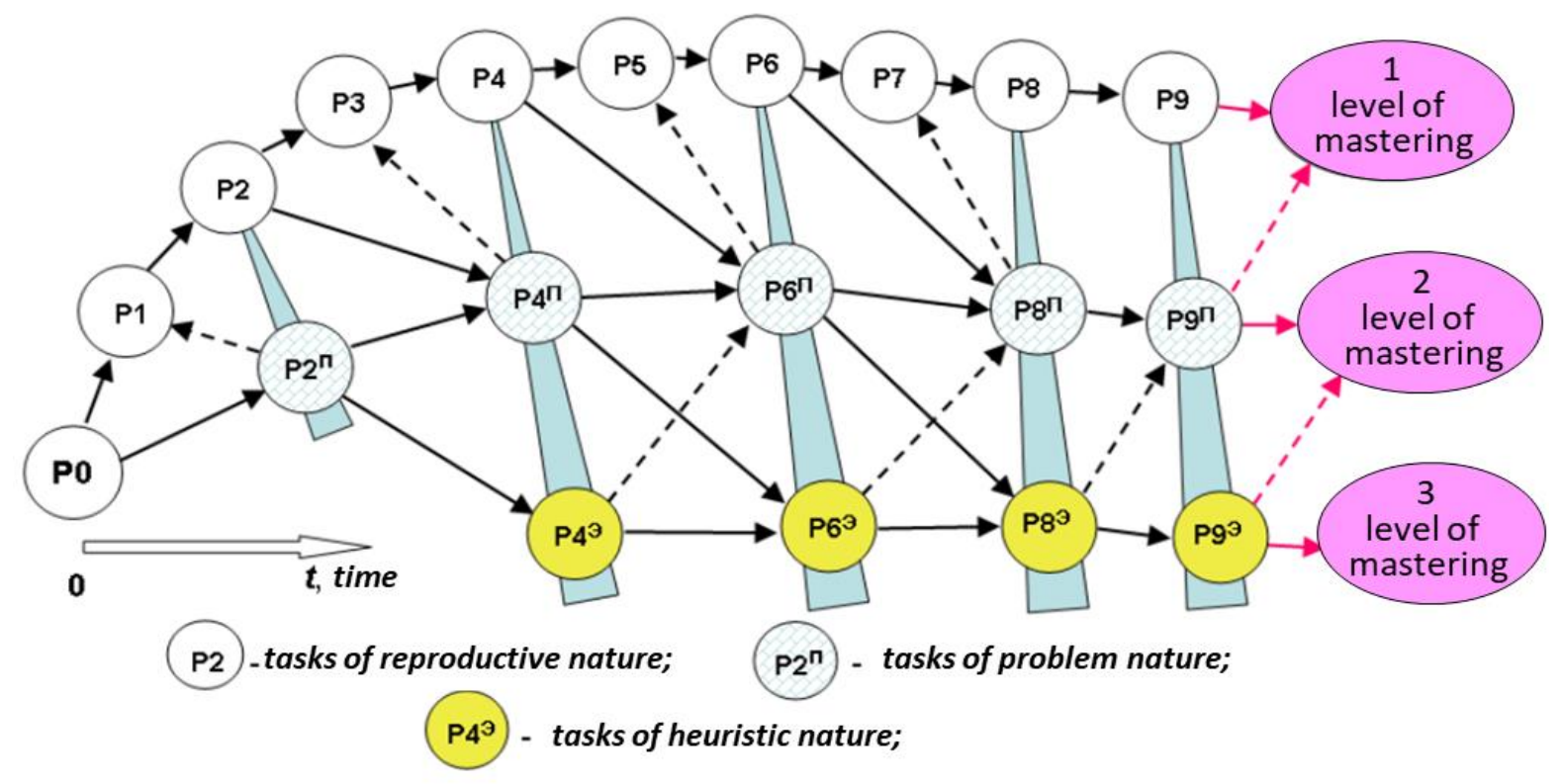

Figure 2: Network planning of individual work within the framework of graphic training

With the network planning of individual activities, the most important problem can be identified the organization of monitoring activities that allow you to assess the level of development of a particular topic and the current achievements of students.

Monitoring of learning outcomes and assessment of the level of competence formation is currently insufficiently organized. In view of this, the organizers of the educational process can freely combine not only well-known methods for assessing the individual achievements of students, but also independently selected means that can assess the development of the latest computer technologies.

The preparation of a set of tasks on various topics of the course being studied involves the creation of different levels of complexity and combines the theoretical and practical material used in educational activities. With the successful completion of such tasks, as well as the possibility of choosing the level of difficulty, students can demonstrate a deep mastery of the studied material. At the same time, in the learning process, the teacher has the opportunity to expand the curriculum. As a result, students have an increased interest in self-development and self-education, there is an opportunity to more fully reveal their creative abilities [4].

In the paper, the authors present examples of planned educational achievements of students when performing tasks from topic No. 4 "Geometric constructions in the formation of an object". In Figure 2 , the results of mastering this topic are designated as P4. The examples of creating $3 \mathrm{~d}$ models in Figures 3 and 4 are objects of various levels of complexity. When creating these objects, students are required to know the algorithms of geometric constructions, including the basics of constructing smooth curves using mates.

An example of completing the assignment of route No. 1 from the network planning schedule is shown in Figure 3. This assignment has the first level of complexity; to complete it, students only need to use the construction of one conjugation to get an object of the desired shape (Figure 3a). To build a solid-state object a small number of basic CAD system operations are used. As an additional condition when completing the task, students are given the opportunity to study the properties of a solid model (Figure $3 \mathrm{~b}$ ), as well as mass-centering characteristics (properties of materials). 


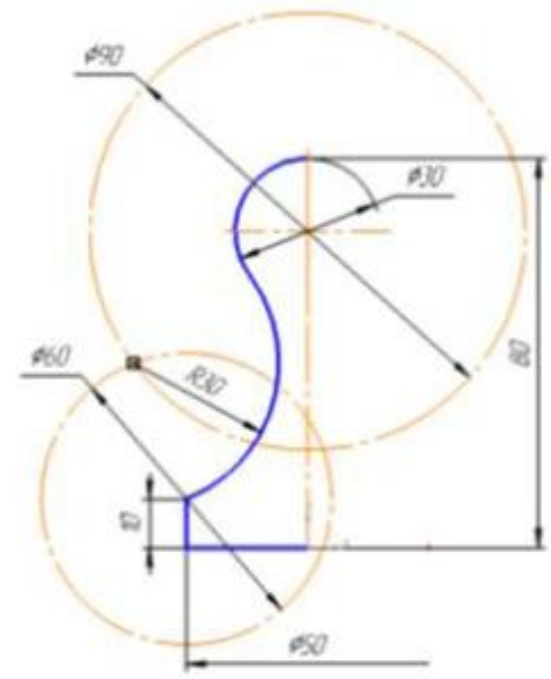

a)
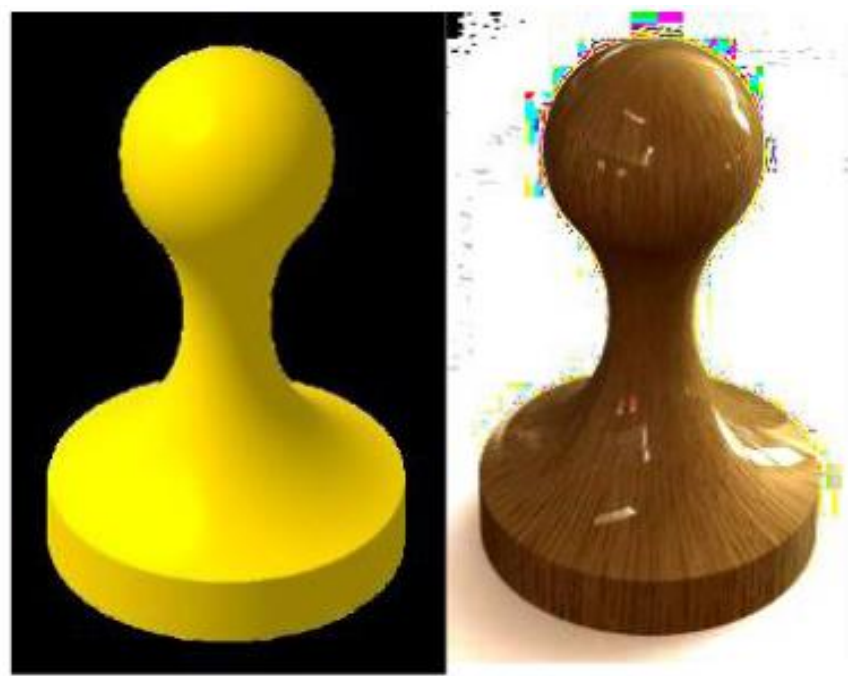

b)

Figure 3: Designing a chess piece: a) virtual creation of the model in CAD; b) visualization options

For route No2, the task, Figure 4 is complicated by increasing the number of contours, complicating the shape of the part due to the presence of additional forming elements. In this case, the task provides for the construction of several interfaces (Figure 4a), which are interconnected with each other. Also, when modeling an object, the teacher has the right to make requirements for the rational implementation of the profile (sketch) of the future model. These requirements consist in a minimum number of imposed parametric connections, including the application of dimensions, and also, if the student uses the "classical" method of contour formation, the requirement is a minimum number of intermediate constructions (Figure 4b).

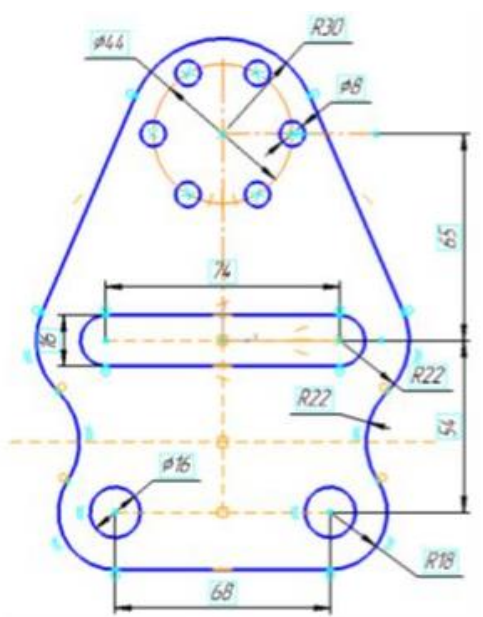

a)

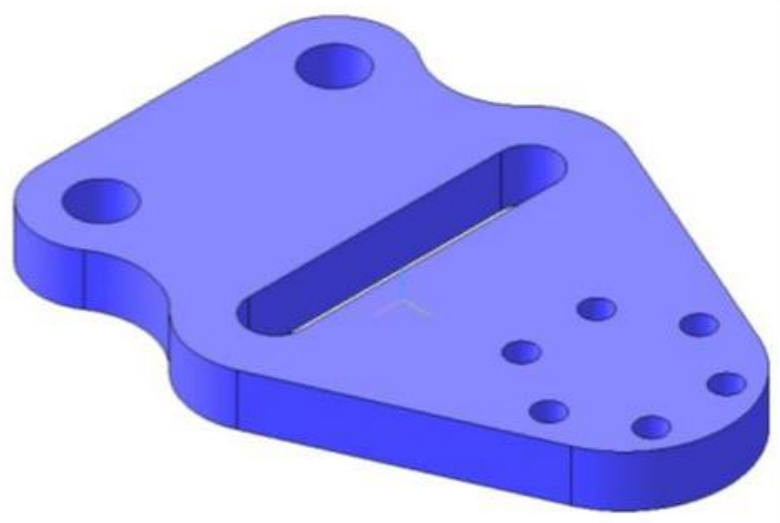

b)

Figure 4: Designing the "Shaped flange" part: a) creating a sketch; b) 3d model of the part

In route No3, a more complex task is provided, which only specifies the key design parameters of the part, and the rest must be formed in the design process, showing creativity and ingenuity. Figure 5 shows one of the task examples, which is a student's independent design solution based on the analysis of the specified parameters and designing the form of the part. The number of operations for forming solid-state elements can vary over a wide range. Evaluation criteria in this task can be the rationality of execution, that is, how optimally the student has built the model, while taking into account the number 
of construction steps. The creative component is also an integral part of the assessment of the assignment. In this case, the student is invited to find the optimal solution in the process of work and create several versions of the model.

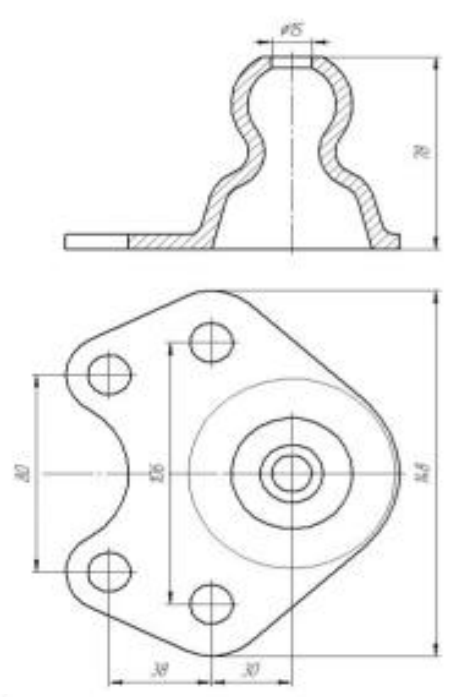

a)

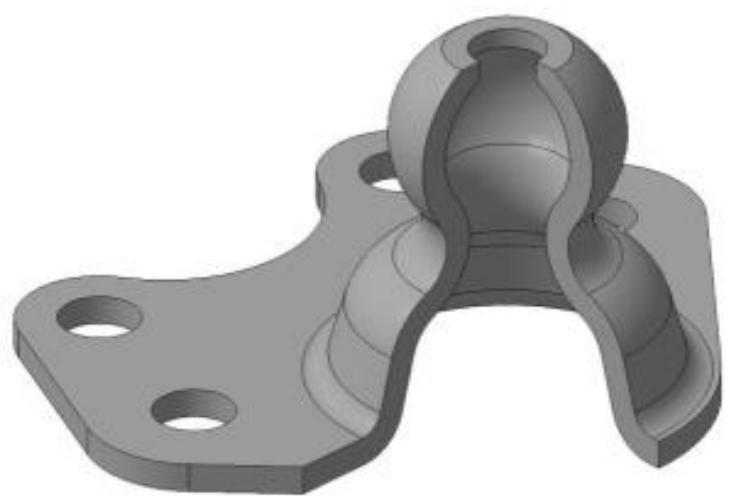

b)

Figure 5: Design of the "Through cover" part, which has a shaped cavity and standard overlays for attaching the part to the body: a) creating a sketch; b) $3 \mathrm{~d}$ model of the part

The presented examples of solving problems of one thematic focus clearly reflect the desire of project tasks to increase complexity. The transition from the lowest level of mastering subject competencies to a higher one is clearly visible.

\section{Conclusion}

Electronic educational resources used for the basic geometric and graphic training of students allow them to conduct training with an approximation to a real professional design environment, as well as introduce students to the latest innovative technologies.

The paper presents a methodology that implies the individualization of the learning process by performing independent tasks by students. Thus, it is possible to note the most important directions for improving graphic education in the conditions of digitalization:

- introduction to the learning process of the basics of open education, which is achieved by the availability of trainees to various network resources;

- information support of the educational process by forms of quasi-professional activity;

- establishing IT contacts between students and the teacher and the constant systematic strengthening of their interaction, carried out "in one language" using the means of the digital world that students use in everyday life;

- $\quad$ using the principles of personalization and individualization of the learning process, which involve taking into account the abilities and capabilities of students, stimulating their personal development and achieving significantly high results in the subject area.

The research presented in the paper, as well as the conclusions drawn on their basis, allow us to see the advantages of using digital educational technologies that take into account the changes that are taking place in economic and socio-cultural life. Such advantages include the ability to organize a new model of training specialists, as well as the actualization of the quality of geometric and graphic training and the ability to create conditions for the continuity of educational and production environments.

\section{References}


[1] I. D. Stolbova, E. P. Aleksandrova, L. V. Kochurova, Organization of graphic education management in terms of digitalization, Informatics and education 9 (2019) (In Russian). doi: 10.32517/0234-0453-2019-34-9-47-55.

[2] E. K. Gitman, M. B. Gitman, V. Yu. Stolbov, I. D. Stolbova, Development and use of FOS in a competence-based format for conducting intermediate certification in the academic discipline. Higher education in Russia 8-9 (2016) 74-83. (In Russian).

[3] N. N. Elyash, Model of contextual learning when performing a workshop on general technical disciplines, Education and Science 1 (2015) (In Russian). doi: 10.17853/1994-5639-2015-1-166175.

[4] I. D. Stolbova, E. P. Alexandrova, K. G. Nosov, Individualization as an integral element of modern higher education, Alma mater (Bulletin of the Higher School) 11 (2016) 48-54. (In Russian).

[5] A.I. Chuchalin, Engineering Education in the Epoch of Industrial Revolution and Digital Economy, Higher Education in Russia 10 (2018) 47-62. (In Russian). doi: 10.31992/0869-36172018-27-10-47-62.

[6] A. O. Gornov, E. V. Usanova, L. A. Shatsillo, To substantiate the GGt paradigm in the projectactivity format, Problems of graphical training quality of students in a technical university: traditions and innovations 5 (2019) 44-64. (In Russian).

[7] E. P. Alexandrova, K. G. Nosov, I. D. Stolbova, Practical implementation of project-oriented activity of students in the course of graphic training, Open education, 5(112) (2015) 55-62. (In Russian). doi: 10.21686/1818-4243-2015-5(112-55-62.

[8] A. B. Puzankova, V. N. Mikhelkevich, Pedagogical system of formation of professional engineering and graphic competencies among students of machine-building profile in the process of their training in computer graphics, Bulletin of Samara state technical university: Psychological and pedagogical sciences 3 (13) (2010) 150-162. (In Russian).

[9] A.A. Zakharova, M.G. Minin Project-oriented training with the use of 3d modeling, Higher education in Russia 1 (2011) 96-101. (In Russian).

[10] I. D. Stolbova, E. P. Alexandrova, L. G. Kochurova, Logic of graphic education innovations, Open and distance education. 2 (2019). (In Russian). doi: 10.17223/16095944/2/4.

[11] T. V. Nikulina, E. B. Tarichenko, Informatization and digitalization of education, Pedagogical education in Russia 8 (2018) 107-113. (In Russian). doi: 10.26170/po18-08-15.

[12] I. N. Kim, Competence-based education in an innovative format, Higher education today 11 (2018) 12-18. (In Russian). doi: 10.25586/RNU.HET.18.11.P.12.

[13] Z. Sh. Aglyamova, Y. L. Kamasheva, D.V. Shevchenko, On one approach to measuring the formation of competencies, Azimuth of scientific research: pedagogy and psychology 2(23) (2018) 15-18. (In Russian). 